\title{
Erratum to: Effect of vaginal estrogen on pessary use
}

\author{
Sybil G. Dessie ${ }^{1,2,3}$ - Katherine Armstrong ${ }^{2,3}$ - Anna M. Modest ${ }^{2}$. \\ Michele R. Hacker ${ }^{2,3} \cdot$ Lekha S. Hota ${ }^{1,2,3,4}$
}

Published online: 20 June 2016

(C) The International Urogynecological Association 2016

\section{Erratum to: Int Urogynecol J}

\section{DOI 10.1007/s00192-016-3000-1}

In the published version of this article, Figs. 2 and 3 captions were interchanged. These figures are presented again below with the correct captions.

The online version of the original article can be found at http://dx.doi.org/ 10.1007/s00192-016-3000-1.

\section{Lekha S. Hota}

lhota@mah.harvard.edu

1 Division of Urogynecology, Department of Obstetrics and Gynecology, Mount Auburn Hospital, Cambridge, MA, USA

2 Department of Obstetrics and Gynecology, Beth Israel Deaconess Medical Center, Boston, MA, USA

3 Department of Obstetrics, Gynecology and Reproductive Biology, Harvard Medical School, Boston, MA, USA

4 Boston Urogynecology Associates/Mount Auburn Hospital, 725 Concord Ave. Suite \#1200, Cambridge, MA 02138, USA

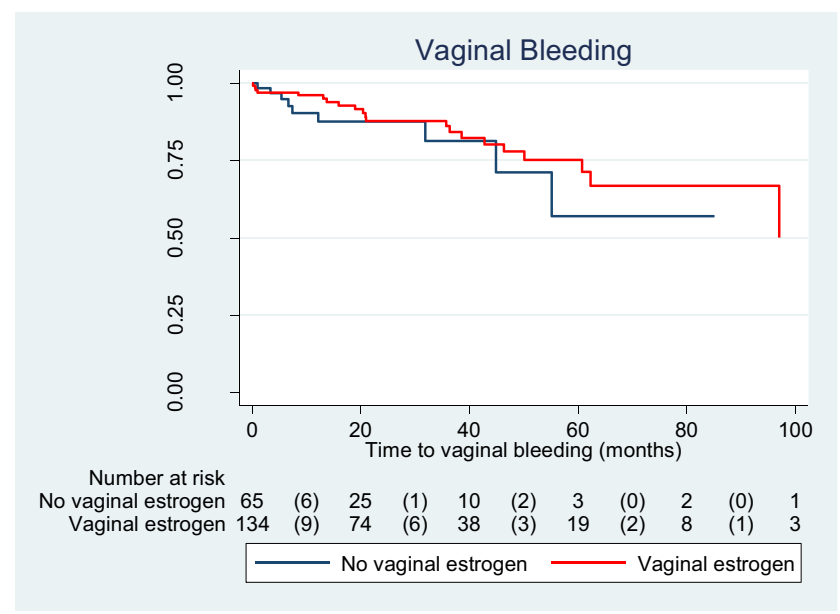

Fig. 2 Time to vaginal bleed among women with pessary use $(n=199)$; $\log$ rank test $P=0.53$



Fig. 3 Increased vaginal discharge among women with pessary use $(n=199), \log$ rank test, $P=0.0001$ 